\title{
Analisis Kekritisan Sodium-Cooled Fast Reactor (SFR) Berdasarkan Variasi Daya Keluaran
}

\author{
Elsa Yolanda Putri ${ }^{1}$,, Mohammad Ali Shafii ${ }^{1}$, Feriska Handayani Irka , Zaki \\ Su'ud \\ ${ }^{1}$ Jurusan Fisika FMIPA Universitas Andalas \\ ${ }^{2}$ LaboratoriumNuklir dan Biofisika Institut Teknologi Bandung \\ *p_elsayolanda@yahoo.com
}

\begin{abstract}
ABSTRAK
Analisis kekritisan Sodium-Cooled Fast Reactor (SFR) berdasarkan variasi daya keluaran telah dilakukan. Reaktor ini menggunakan uranium alam sebagai bahan bakar dan natrium sebagai pendingin. Parameter yang diamati adalah faktor multiplikasi $\left(\mathrm{k}_{\text {eff }}\right.$ dan $\left.\mathrm{k}_{\text {inf }}\right)$. Penelitian ini dilakukan secara simulasi komputasi menggunakan kode SRAC dengan JENDL-32 sebagai library. Model teras adalah cylinder dua dimensi R-Z dengan lima variasi daya keluaran yaitu 300, 350, 400, 450, dan 500 MWTh. Teras reaktor dibagi menjadi 11 region radial dan 2 region aksial. Sepuluh region pertama merupakan region untuk menempatkan bahan bakar sedangkan region ke sebelas adalah reflektor. Pada awal operasi reaktor, masing-masing region diisi dengan bahan bakar uranium alam. Setelah 10 tahun pembakaran, hasil burn up pada region 1 di shuffling ke region 2, hasil burn up region 2 di shuffling ke region 3, dan seterusnya sampai hasil burn up region 9 di shuffling ke region 10 dan hasil burn up region 10 dikeluarkan dari teras reaktor sehingga region 1 dapat diisi dengan bahan bakar baru (fresh fuel). Proses ini dilakukan sampai 100 tahun operasi reaktor. Hasil penelitian menunjukkan bahwa daya keluaran 300 MWTh mempunyai nilai kekritisan yang mendekati nilai 1 (reaktor dalam keadaan kritis menandakan jumlah populasi neutron pada satu generasi sama dengan generasi sebelumnya).

Kata kunci: burn up, kekritisan, SFR, shuffling, uranium alam.
\end{abstract}

\begin{abstract}
The analysis of the criticality of the Sodium-Cooled Fast Reactor (SFR) based on the variations of power output has been done. This reactor uses natural uranium as a fuel and natrium as a coolant. Parameter that observed is the multiplication factor. This research is a simulated computing using the SRAC code with JENDL-32 as a library. Two dimensions $R-Z$ core cylinder model with five variation of power output which are 300, 350, 400, 450, and 500 MWTh. The reactor core is divided into eleven radial regions and two axial regions. Ten first regions are a regions for placing the fuel while the eleventh regions are a reflector. At the beginning of the reactor operation, each region is filled with natural uranium fuel. After 10 years of burning, the results of burn up in the $1^{\text {st }}$ region is shuffled into $2^{\text {nd }}$ region, the results of burn up of $2^{\text {nd }}$ region is shuffled to $3^{\text {rd }}$ region and so on until the results of burn up the $9^{\text {th }}$ region shuffled to $10^{\text {th }}$ region and the results of burn up the $10^{\text {th }}$ region removed from the reactor core so the $1^{\text {st }}$ region can be filled with new fuel (fresh fuel). This process is performed up to 100 years of the operation of reactor. The results showed that the power output 300 MWTh have a value of criticality that approach the value of 1 (the reactor in a critical state indicates the number of the population of neutrons in one generation is equal to the previous generation).

Keywords : burn up, criticality, shuffling, uranium nature
\end{abstract}

\section{PENDAHULUAN}

Kebutuhan masyarakat mengenai energi di Indonesia semakin meningkat. Menurut proyeksi Badan Energi Dunia (International Energy Agency-IEA), hingga tahun 2030 permintaan energi meningkat $45 \%$ atau rata-rata $1,6 \%$ per tahun, sedangkan kebutuhan energi di Indonesia naik sebesar 6\% per tahun. Hal ini mengakibatkan kebutuhan masyarakat terhadap energi beberapa waktu ke depan akan semakin sulit terpenuhi. Sebagian besar atau sekitar $80 \%$ kebutuhan energi dunia tersebut dipasok dari bahan bakar fosil (Kementrian ESDM, 2016). Bahan bakar fosil merupakan sumber energi tidak terbarukan dan menyumbang 33\% karbon di atmosfer per tahun yang berdampak pada efek pemanasan global (Ashby dan Smidman, 2010). Salah satu solusi sumber energi alternatif yang cukup menjanjikan adalah energi nuklir yang menggunakan energi hasill reaksi fisi.

Secara umum energi nuklir dihasilkan melalui dua mekanisme yaitu pembelahan inti atau reaksi fisi dan reaksi fusi atau penggabungan inti (Duderstadt dan Hamilton, 1976). 
Pembelahan inti atau reaksi fisi merupakan mekanisme yang digunakan untuk menghasilkan energi nuklir dalam sebuah reaktor. Perkembangan reaktor semakin maju seiring dengan peningkatan kebutuhan energi. Perkembangan ini dimaksudkan untuk menghasilkan reaktor nuklir modern dengan sistem keamanan dan keandalan yang tinggi, efisiensi bahan bakar tinggi, dan limbah nuklir rendah. Salah satu jenis raektor modern adalah reaktor generasi IV.

Analisis neutronik merupakan salah satu aspek yang perlu ditinjau dalam perancangan reaktor nuklir. Analisis neutronik membahas mengenai reaksi fisi yang terjadi di dalam elemen bahan bakar. Salah satu parameter neutronik yaitu densitas nuklida yang menggambarkan rapat massa atom pada teras reaktor. Penelitian mengenai analisis neutronik pada reaktor cepat telah banyak dilakukan. Penelitian yang dilakukan oleh Guska (2015) dengan reaktor LFR berdasarkan variasi daya keluaran menunjukkan bahwa reaktor LFR dengan daya keluaran 300 (MWTh) mempunyai nilai faktor multiplikasi neutron dan burn up yang paling optimal dengan nilai $k_{\text {eff }}$ per periode burn up mendekati nilai 1 (reaktor dalam keadaan kritis). Analisis neutronik reaktor cepat oleh Nurwinda (2009) dengan menvariasikan bahan pendingin $(\mathrm{Na}, \mathrm{Pb}, \mathrm{Pb}-\mathrm{Bi})$ dan hasil yang didapatkan bahan pendingin yang menggunakan $\mathrm{Pb}-\mathrm{Bi}$ pada reaktor cepat memberikan karakteristik neutronik yang paling optimal.

Analisis neutronik oleh Cinantya (2014) pada reaktor cepat berpendingin $\mathrm{Pb}-\mathrm{Bi}$ dengan variasi bahan bakar (UN-PuN, UC-PuC, dan MOX) hasil penelitian menunjukkan bahwa bahan bakar UN-PuN memiliki distribusi fluks neutron dan distribusi daya yang paling besar serta juga memiliki karakteristik neutronik yang paling optimal dibandingkan dengan bahan bakar lain. Rida (2007) dengan desain tinggi teras dan diameter teras aktif $250 \mathrm{~cm}$ dan $200 \mathrm{~cm}$, pembagian teras 6 region yang menggunakan perbandingan fraksi bahan bakar, cladding, dan coolant sebesar 51\%, 14\% dan 35\% menghasilkan daya keluaran 1500 MWTh.

Untuk melengkapi informasi mengenai karakteristik Sodium-Cooled Fast Reactor (SFR) secara menyeluruh masih banyak aspek yang perlu ditinjau, diantaranya densitas nuklida dan memvariaisikan daya keluaran reaktor, untuk itu pada penelitian ini dilakukan variasi daya keluaran yang digunakan adalah 300, 350, 400, 450, dan 500 MWth. Penelitian ini bertujuan untuk menganalisis reaktor SFR berdasarkan variasi daya keluaran.

\section{METODE}

Penelitian ini dilakukan di Laboratorium Fisika Nuklir, Universitas Andalas, Padang. Perhitungan teras menggunakan kode komputer SRAC yang dikembangkan oleh JAEA (Japan Atomic Energy Agency). SRAC terdiri dari beberapa perpustakaan data nuklir yang diturunkan dari ENDF/B-IV (R2 dan R5), JENDL-3.1, JENDL-3.2, dan JEF-2.2. Versi yang telah dimodifikasi dari lima kode modulas sudah terintegrasi dalam SRAC95; modul perhitungan probabilitas tumbukan (PIJ) untuk 16 tipe kisi geometri, modul perhitungan difusi (TUD, CITATION) dan dua kode pilihan untuk assembly bahan bakar dan perhitungan burn up teras (Okumura dkk, 2006).

Desain reaktor yang digunakan adalah reaktor cepat berpendingin natrium dengan spektrum neutron cepat menggunakan strategi shuffling arah radial. Strategi ini diterapkan agar reaktor dapat beroperasi menggunakan bahan bakar uranium alam. Desain teras yang digunakan pada penelitian ini bertipe cylinder 2-D dikarenakan, jika ditinjau dari faktor kebocoran neutron (neutron leakage) dan aliran coolant maka geometri silinder yang paling optimal. Spesifikasi yang digunakan yaitu fraksi bahan bakar $51 \%$, fraksi struktur 35\%, fraksi pendingin $14 \%$ diameter pin $1,4 \mathrm{~cm}$, tinggi teras aktif $2,5 \mathrm{~m}$, lebar reflektor $50 \mathrm{~cm}$ dan burn up material bahan bakar yang dilakukan yaitu 100 tahun. Geometri teras dan pembagian region dapat dilihat pada Gambar 1 dan diagram alir perhitungan desain reaktor dengan SRAC dapat dilihat pada Gambar 2. 


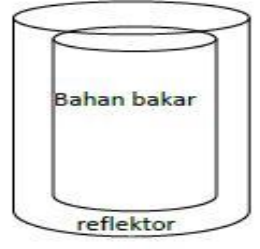

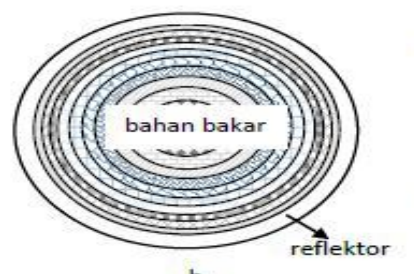

b

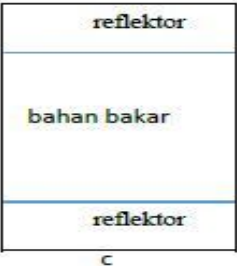

Gambar 1 (a) Geometri teras, (b) Pembagian region arah radial (11 region), (c) Pembagian region arah aksial (2 region)

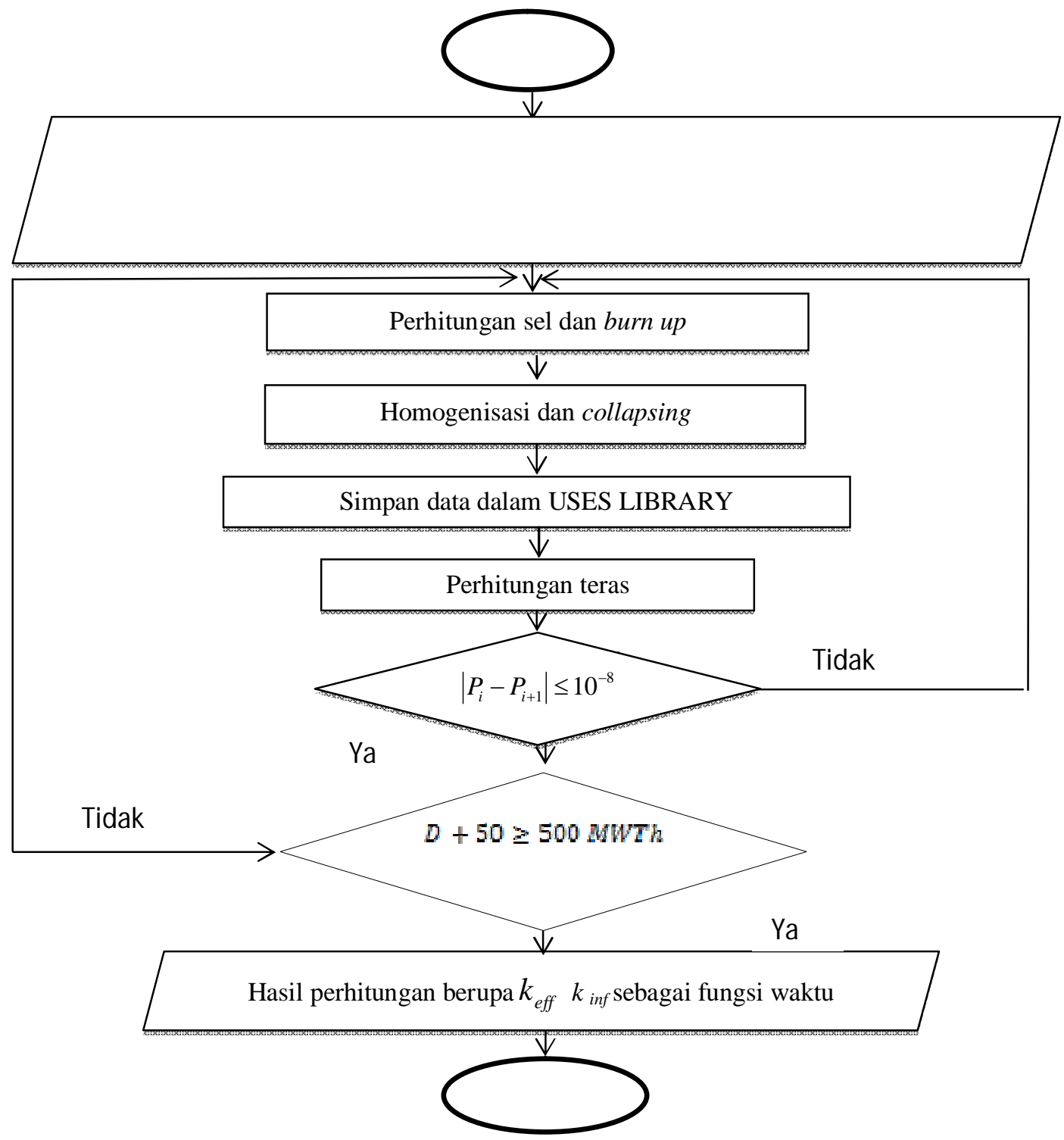

Gambar 2 Diagram alir perhitungan neutronik menggunakan SRAC

\section{HASIL DAN DISKUSI}

Dengan menggunakan motede perhitungan berdasarkan diagram alir pada Gambar 2 diperoleh nilai $\mathrm{k}_{\text {eff. }}$ Nilai $\mathrm{k}_{\text {eff }}$ merupakan nilai perbandingan jumlah populasi neutron dalam teras reaktor pada satu generasi dengan generasi sebelumnya, dapat dilihat pada Gambar 3. 


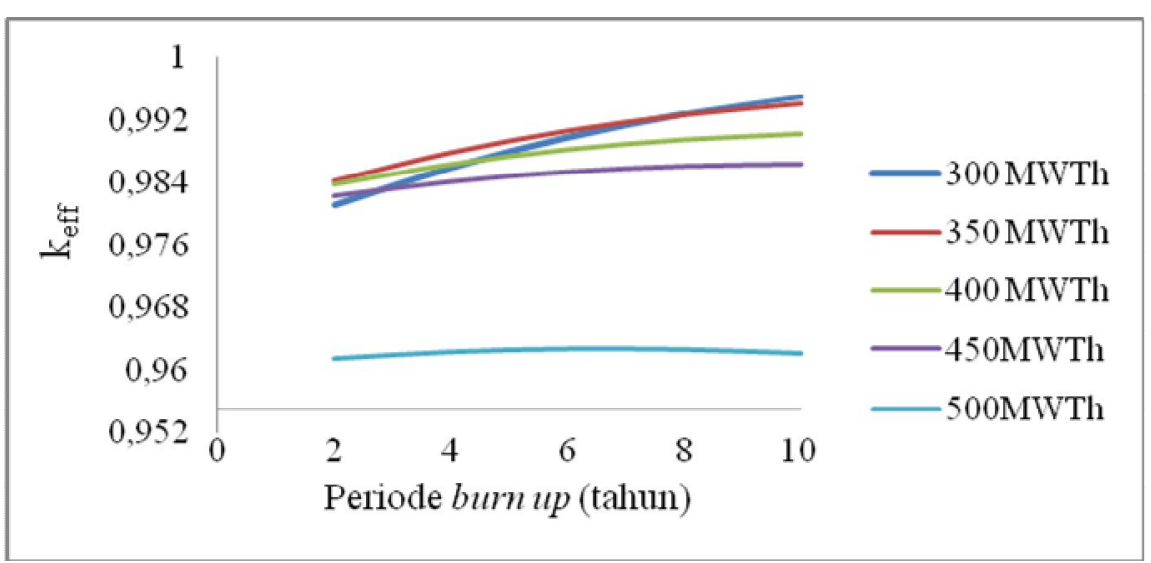

Gambar 3 Hubungan $k_{\text {eff }}$ terhadap periode level burn up untuk berbagai variasi daya keluaran

Gambar 3 memperlihatkan hubungan $k_{\text {eff }}$ terhadap periode burn up yang dilakukan selama 10 tahun. Periode burn up 10 tahun dipilih karena untuk melihat $k_{\text {eff }}$ setiap 10 tahun. Siklus ini dilakukan selama 100 tahun periode burn up. Gambar 3 menunjukkan nilai $\mathrm{k}_{\text {eff }}$ yang diperoleh semakin mendekati 1bila daya keluaran makin kecil. Dari semua daya keluaran yang dirancang terlihat bahwa reaktor berada dalam keadaan kritis pada daya keluaran 300 MWTh terbukti dari nilai $\mathrm{k}_{\text {eff }}$ per periode burn upnya mendekati 1 . Reaktor dalam keadaan kritis menandakan jumlah populasi neutron pada satu generasi sama dengan generasi sebelumnya.

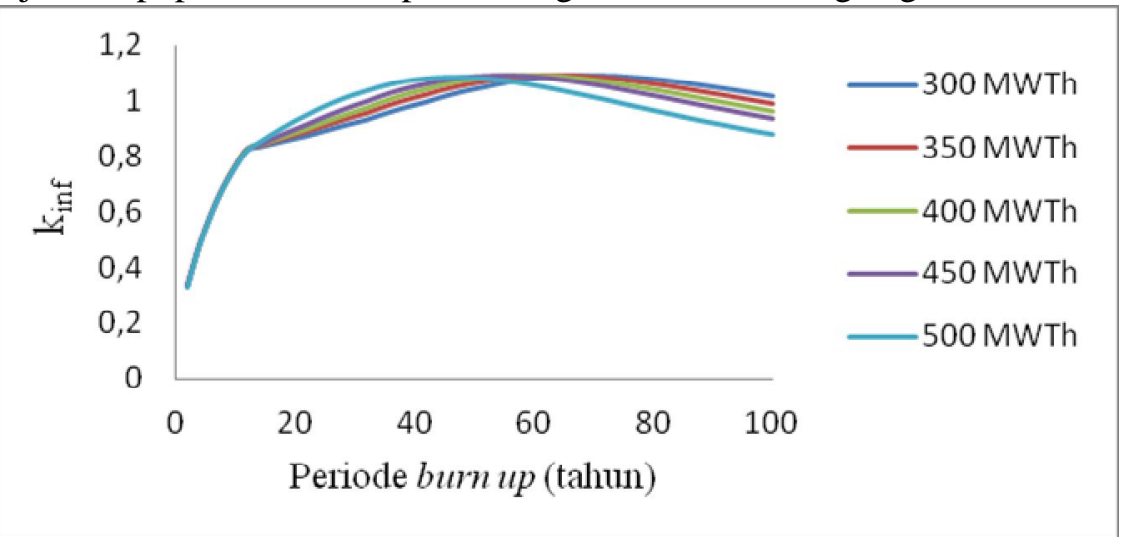

Gambar 4 Hubungan $k_{\text {inf }}$ terhadap level burn up untuk berbagai variasi daya keluaran

Faktor multiplikasi infinite (kinf) adalah perbandingan neutron pada satu generasi dengan generasi sebelumnya tanpa adanya kebocoran neutron. Gambar 4 merupakan hasil kinf yang di dapatkan dari perhitungan sel, terlihat bahwa pada 20 tahun awal periode burn up nilai kinf belum mencapai 1 . Setelah lebih dari 20 tahun periode burn up, kinf mengalami peningkatan secara bertahap mencapai nilai lebih dari 1 yaitu pada daya keluaran 300 MWTh, sedangkan pada daya 350 MWTh, 400 MWTh, 450 MWTh dan 500 MWTh mengalami penurunan yang bertahap dan memiliki nilai kinf kecil dari 1 dikarenakan pada awal periode burn up bahan fisil yang ada di dalam teras reaktor kuantitasnya sedikit, seiring dengan bertambahnya level burn up, bahan fertil $238 \mathrm{U}$ telah menghasilkan bahan fisil $239 \mathrm{Pu}$ yang mengakibatkan populasi neuton meningkat dan nilai kinf mencapai nilai 1.

\section{KESIMPULAN}

Berdasarkan analisis hasil penelitian dapat disimpulkan bahwa rancangan teras reaktor yang mempunyai nilai faktor multiplikasi (keff dan kinf) per periode burn up mendekati nilai 1 (reaktor dalam keadaan kritis) yaitu pada daya keluaran 300 MWTh. Hasil nilai untuk kinf yang per periode burn up nilainya lebih dari 1 yaitu pada daya keluaran 300 MWTh dikarenakan bahan fertil $238 \mathrm{U}$ telah menghasilkan bahan fisil $239 \mathrm{Pu}$ yang mengakibatkan populasi neutron meningkat dan nilai kinf mencapai nilai 1 . 
DAFTAR PUSTAKA

Cinatya N, D., "Analisis Neutronik Pada Reaktor Cepat Dengan Variasi Bahan Bakar (UNPuN, UC-PuC, dan MOX)", Skripsi S1, Jurusan Fisika Universitas Andalas, 2014.

Duderstadt, J.J., and Hamilton, L.J, 1976, Nuclear Reactor Analysis John Wiley \& Sons, Inc., (NewYork).

Guskha, C.R., Jurnal Fisika Unand. 5, 7-13 (2015).

Nurwinda, Analisis Difusi Neutronik pada Reaktor Cepat Dengan Variasi Bahan Pendingin ( $\mathrm{Na}, \mathrm{Pb}, \mathrm{Pb}-\mathrm{Bi})$, Skripsi, Jurusan Fisika UNAND, Padang, 2009.

Okumura, K., Kugo, T., Kaneko, K., and Thuchihashi, K., 2006, A Neutroniscs Calculation Code System, Japan, JAEA.

Rida, SNM., 2007, Design Study of Long Life Pb-Bi Cooled Reactors With Natural Uranium as Fuel Cycle Input Using Radial Fuel Shuffling Strategy, Proceeding of International Conference on Advances in Nuclear Science and Engineering in Conjunction with LKSTN 2007, ITB, hal. 257-261.

Kementrian, ESDM, 2016, Permintaan Energi Dunia Meningkat hingga 2030, http://www.kementrianesdm.go.id20130 permintaan-energi-dunia-mening-kat-45\%html, diakses Agustus 2017. 